\title{
Silibinin modulates lipid homeostasis and inhibits nuclear factor kappa B activation in experimental nonalcoholic steatohepatitis
}

\author{
FEDERICO SALAMONE, FABIO GALVANO, FRANCESCO CAPPELLO, ANDREA MANGIAMELI, \\ IGNAZIO BARBAGALLO, and GIOVANNI LI VOLTI
}

CATANIA, PALERMO, AND SAN DONATO MILANESE (MI), ITALY

\begin{abstract}
Nonalcoholic steatohepatitis (NASH) is associated with increased liver-related mortality. Disturbances in hepatic lipid homeostasis trigger oxidative stress and inflammation (ie, lipotoxicity), leading to the progression of NASH. This study aimed at identifying whether silibinin may influence the molecular events of lipotoxicity in a mouse model of NASH. Eight-week-old $\mathrm{db} / \mathrm{db}$ mice were fed a methioninecholine deficient (MCD) diet for 4 weeks and treated daily with silibinin $(20 \mathrm{mg} / \mathrm{kg}$ intraperitoneally) or vehicle. Liver expression and enzyme activity of stearoyl-CoA desaturase- 1 and acyl-CoA oxidase, and expression of liver fatty acid-binding protein were assessed. Hepatic levels of reactive oxygen species, thiobarbituric acidreactive substances (TBARS), 3-nitrotyrosine (3-NT), inducible nitric oxide synthase (iNOS), and nuclear factor kappa B (NFkB) activities were also determined. Silibinin administration decreased serum alanine aminotransferase and improved liver steatosis, hepatocyte ballooning, and lobular inflammation in $\mathrm{db} / \mathrm{db}$ mice fed an MCD diet. Gene expression and activity of stearoyl-CoA desaturase-1 were reduced in $\mathrm{db} / \mathrm{db}$ mice fed an MCD diet compared with lean controls and were increased by silibinin; moreover, silibinin treatment induced the expression and activity of acylCoA oxidase and the expression of liver fatty acid-binding protein. Vehicle-treated animals displayed increased hepatic levels of reactive oxygen species and TBARS, 3-NT staining, and iNOS expression; silibinin treatment markedly decreased reactive oxygen species and TBARS and restored 3-NT and iNOS to the levels of control mice. $\mathrm{db} / \mathrm{db}$ mice fed an MCD diet consistently had increased NFkB p65 and p50 binding activity; silibinin administration significantly decreased the activity of both subunits. Silibinin treatment counteracts the progression of liver injury by modulating lipid homeostasis and suppressing oxidative stress-mediated lipotoxicity and NFkB activation in experimental NASH. (Translational Research 2012;159:477-486)
\end{abstract}

\begin{abstract}
Abbreviations: $\mathrm{AOX}=$ acyl-CoA oxidase; $\mathrm{ALT}=$ alanine aminotransferase; $\mathrm{FFA}=$ free fatty acid; iNOS = inducible nitric oxide synthase; L-FABP = liver-fatty acid binding protein; $\mathrm{MCD}=$ methionine-choline deficient; NAFLD = nonalcoholic fatty liver disease; NASH = nonalcoholic steatohepatitis; $\mathrm{NFkB}=$ nuclear factor kappa $\mathrm{B}$; $\mathrm{NO}=$ nitric oxide; $\mathrm{PCR}=$ polymerase chain reaction; RNS = reactive nitrogen species; $R O S=$ reactive oxygen species; $S D=$ standard diet; SCD-1 = stearoyl-CoA desaturase 1; TBARS = thiobarbituric acid-reactive substances; 3-NT = 3-nitrotyrosine
\end{abstract}

From the Department of Internal Medicine, University of Catania, Catania, Italy; Department of Drug Sciences, University of Catania, Catania, Italy; Department of Experimental Medicine, University of Palermo, Palermo, Italy; Istituto Euro Mediterraneo di Scienza e Tecnologia, Palermo, Italy; Department of Cardiac Surgery, San Donato Institute, San Donato Milanese (MI), Italy.

Conflicts of Interest: none.

Submitted for publication October 27, 2011; revision submitted December 5, 2011; accepted for publication December 6, 2011.
Reprint requests: Federico Salamone, MD, PhD, Dipartimento di Medicina Interna, Università di Catania, Via Santa Sofia, 78, 95123 Catania, Italy; e-mail: federicosalamone @ yahoo.it.

$1931-5244 / \$$ - see front matter

(c) 2012 Mosby, Inc. All rights reserved.

doi:10.1016/j.trs1.2011.12.003 


\section{AT A GLANCE COMMENTARY}

Salamone $F$, et al.

Background

NASH is associated with increased liver-related mortality. No pharmacologic treatment has been shown to be effective for NASH. Polyphenols can modulate the molecular pathways involved in liver steatogenesis and are able to counteract oxidative stress and inflammation.

\section{Translational Significance}

We demonstrated that silibinin exerts antisteatotic effects because of changes in liver expression of key enzymes involved in lipid homeostasis. Moreover, silibinin counteracts liver injury progression via antioxidant and anti-inflammatory activity. On the basis of these findings, there is a significant molecular rationale for the use of silibinin in patients with NASH.

Nonalcoholic fatty liver disease (NAFLD) is a chronic metabolic disorder with significant impact on all-cause mortality. ${ }^{1}$ NAFLD is independently associated with the features of the metabolic syndrome, ${ }^{2,3}$ having insulin resistance as a common metabolic determinant. ${ }^{4}$ NAFLD includes a wide spectrum of histologic lesions ranging from nonalcoholic fatty liver to nonalcoholic steatohepatitis (NASH). ${ }^{5} \mathrm{NASH}$ is characterized by hepatocellular damage (ie, ballooning and inflammation) and may have a fibrogenic evolution leading to liverrelated morbidity and mortality. ${ }^{1}$ Patients with NASH have increased liver content of free fatty acids (FFAs) derived from adipose tissue lipolysis and hepatic de novo lipogenesis. ${ }^{6}$ An imbalance in the production and scavenging of reactive oxygen species (ROS) and reactive nitrogen species (RNS), mainly derived from mitochondrial FFA oxidation, can cause hepatocyte injury and may trigger the activation of inflammatory signaling (eg, nuclear factor kappa $\mathrm{B}[\mathrm{NFkB}]$ ) in the liver. $^{7,8}$

Several pharmacologic treatments have been proposed for NASH, but currently available drugs have been reported to have limited efficacy and safety. ${ }^{9}$ Experimental studies suggest that some natural polyphenols may be effective in counteracting oxidative stress and inflammation in NASH. ${ }^{10}$ Silibinin is a polyphenolic compound contained in silymarin, a mixture of flavonolignans extracted for milk thistle (Silybum marianum) seeds, widely used as hepatoprotectant, although its molecular effects are not fully understood. Potent scavenging properties have been demonstrated in hepatic and non-hepatic cells; ${ }^{11,12}$ several in vivo studies showed that silibinin may exert beneficial effects in different types of liver injury ${ }^{13,14}$ and in diabetes and its complications. ${ }^{15}$

Previous clinical findings evidenced the efficacy of silibinin on insulin resistance and liver injury, assessed by surrogate markers, in patients with NASH; ${ }^{16}$ the improvement of liver histology after silibinin treatment was recently reported in a multicenter randomized controlled trial. ${ }^{17}$ However, the molecular mechanisms associated with the hepatoprotective activity of silibinin in NASH remain to be elucidated. The current study aimed at clarifying whether silibinin may favorably affect lipogenesis, oxidative stress, and NFkB activation in a mouse model of NASH. To this aim, we examined the effects of silibinin administration in $\mathrm{db} / \mathrm{db}$ mice fed a methionine-choline deficient (MCD) diet, an experimental model combining the features of the metabolic syndrome with the histologic pattern of NASH. ${ }^{18,19} \mathrm{db} /$ $\mathrm{db}$ mice fed an MCD diet partially conserve the $\mathrm{db} / \mathrm{db}$ phenotype, mainly increased visceral adiposity, ${ }^{19}$ while developing hepatocellular injury and inflammation typical of the MCD diet. ${ }^{18,19}$

\section{METHODS}

Animals and treatments. Eight-week-old male BKS.Cg-m $+/+$ Leprdb/J (db/db) obese mice and 8-week-old male heterozygous $\mathrm{db} / \mathrm{m}$ lean control mice were purchased from Charles River Laboratories (Calco, Italy). Animals were maintained in a temperature- and light-controlled facility and permitted ad libitum consumption of water; $\mathrm{db} / \mathrm{db}$ mice were fed an MCD diet (ICN Biomedicals, Costa Mesa, Calif) for 4 weeks; $\mathrm{db} / \mathrm{m}$ mice were fed an MCD diet supplemented with methionine and choline (ICN Biomedicals), that is, a standard diet (SD), for the same period. Mice were distributed in 3 groups: Group I included $8 \mathrm{db} / \mathrm{m}$ mice fed a control diet and treated with vehicle $(\mathrm{db} / \mathrm{m}+\mathrm{SD})$; group II included 8 $\mathrm{db} / \mathrm{db}$ mice fed an MCD diet and treated with vehicle $(\mathrm{db} / \mathrm{db}+\mathrm{MCD})$; group III included $8 \mathrm{db} / \mathrm{db}$ mice fed an MCD diet and treated with silibinin $(\mathrm{db} / \mathrm{db}+$ MCD + silibinin). Silibinin dihydrogen succinate (Indena, Milan, Italy) was dissolved in saline and administered daily intraperitoneally at a dosage of $20 \mathrm{mg} / \mathrm{kg}$ of body weight. This dosage has been showed to be safe both in healthy volunteers ${ }^{20}$ and in patients with chronic hepatitis C. ${ }^{21,22}$ Treatment was administered for a 4-week period; at the end of treatment, animals were sacrificed after an overnight fast. Blood and liver samples were processed and 
stored for further analysis. All procedures were carried out in accordance with the "Italian Guidelines for the Care and Use of Laboratory Animals," and the article conforms to the relevant ethical guidelines for animal research.

Histopathology and immunofluorescence. Formalinfixed, paraffin-embedded sections of hepatic tissue were stained with hematoxylin-eosin using standard procedures. Liver sections were also stained with Masson's trichrome. NAFLD lesions were blindly evaluated following the NAFLD activity score. Immunofluorescence with 3-nitrotyrosine (3-NT) (Chemicon Inc, Pittsburgh, Pa) antibody was performed on liver sections using standard protocols.

Biochemical analyses. Blood glucose was measured by ACCU-CHEK (Roche Diagnostics, Milan, Italy). Serum aspartate aminotransferase, alanine aminotransferase (ALT), and serum insulin were determined using a multichannel autoanalyzer (Abbott Diagnostics, Milan, Italy). Thiobarbituric acid-reactive substances (TBARS) were measured by a TBARS assay kit (Cayman, Ann Arbor, Mich).

ROS measurement. ROS generation was determined in tissue homogenates by using 2',7'-dichlorodihydrofluoroscein diacetate as a probe. Dichlorodihydrofluorescein diacetate formation was determined fluorometrically with a Hitachi F-2000 (Hitachi Ltd, Tokyo, Japan) fluorescence spectrophotometer at excitation wavelength of $488 \mathrm{~nm}$ and emission wavelength of $525 \mathrm{~nm}$ at $37^{\circ} \mathrm{C}$.

Western blot analysis. Whole liver homogenates were processed for Western blot analysis, and protein levels were visualized by immunoblotting with antibodies against the inducible nitric oxide synthase (iNOS) (Chemicon, Temecula, Calif). Briefly, $30 \mu \mathrm{g}$ protein was separated by sodium dodecyl sulphatepolyacrylamide gel electrophoresis and transferred to a nitrocellulose membrane (Amersham Inc, Piscataway, NJ) using a semidry transfer apparatus (Bio-Rad, Hercules, Calif). Membranes were incubated with a 1:1.000 dilution of specific antibody overnight with constant shaking. The filters were then washed and subsequently probed with goat anti-rabbit antibodies labeled with IRDye 680 (1:10.000 dilution, LI-COR Biosciences, Lincoln, Neb), and hybridization signals were detected with the Odyssey Infrared Imaging System (LI-COR Biosciences). Densitometric analysis was then performed and normalized with relative actin (Chemicon).

RNA extraction and real-time polymerase chain reaction. Total RNA was extracted by homogenizing snap-frozen liver samples in TRIzol reagent (Invitrogen, Milan, Italy). Quantitative real-time polymerase chain reaction (PCR) was performed in 7900HT Fast Real-Time PCR System (Applied
Biosystems, Foster City, Calif), using the EXPRESS SYBR GreenER qPCR SuperMix with Premixed ROX (Invitrogen). The following primer sequences were used: acyl-CoA oxidase (AOX) forward 5'-CTTG TTCGCGCAAGTGAGG- ${ }^{\prime}$, reverse $5^{\prime}$-CAGGATCC GACTGTTTACC-3'; liver-fatty acid binding protein (L-FABP) forward $5^{\prime}$-GTGGTCCGCAATGAGTTC AC-3', reverse 5'-GTATTGGTGATTGTGTCTCC-3'; and stearoyl-CoA desaturase 1 (SCD-1) forward $5^{\prime}$ TGGGTTGGCTGCTTGTG-3' ， reverse $5^{\prime}$-GCGTGG GCAGGATGAAG- $3^{\prime}$. Reactions were performed in a $20-\mu \mathrm{L}$ mixture containing cDNA, specific primers of each gene, and the SYBRR GreenER qPCR SuperMix. The specific PCR products were detected by the fluorescence of SYBR Green, the double-stranded DNA binding dye. The relative mRNA expression level was calculated by the threshold cycle value of each PCR product and normalized with that of GAPDH by using the comparative $2^{\wedge} \Delta \Delta$ threshold cycle method.

Enzyme activities. Liver AOX activity was measured spectrophotometrically by following the increase in absorbance at $263 \mathrm{~nm}$. A molar extinction coefficient of $6700 \mathrm{M}^{-1} \times \mathrm{cm}^{-1}$ was used as previously described. ${ }^{23}$ Liver SCD-1 activity was performed after extraction and fractionation of long-chain acyl-CoAs by reversephase high-performance liquid chromatography as previously reported. ${ }^{24}$ Chromatographically resolved stearoyl-CoA (C18:0) and oleyl-CoA (C18:1) peaks were collected and counted in a $\beta$-scintillation counter. The protein content was determined according to the Bradford method. ${ }^{25}$

Extraction of nuclear proteins and activity assays. Nuclei were isolated using the Pierce Isolation Kit (Thermo Fisher Scientific, Rockford, IL) following the manufacturer's instructions. Nuclear extracts were resuspended in specific buffer, and protein content was obtained according to the Bradford method. Subsequently, activated p50 and p65 were measured by a specific Trans-AM transcription factor assay kit (Active Motif, Rixensart, Belgium) according to the manufacturer's instructions. In this assay, an oligonucleotide containing the NFkB consensus site is attached to a 96-well plate. The active form of transcription factor contained in nuclear extracts specifically binds to this oligonucleotide and can be revealed by incubation with specific antibodies using enzyme-linked immunosorbent assay technology with absorbance reading.

Statistical analysis. Statistics were performed by GraphPad Prism (GraphPad, San Diego, Calif). All results were expressed as mean \pm standard error of the mean. One-way analysis of variance with Bonferroni post hoc analysis was used for parametric data. 

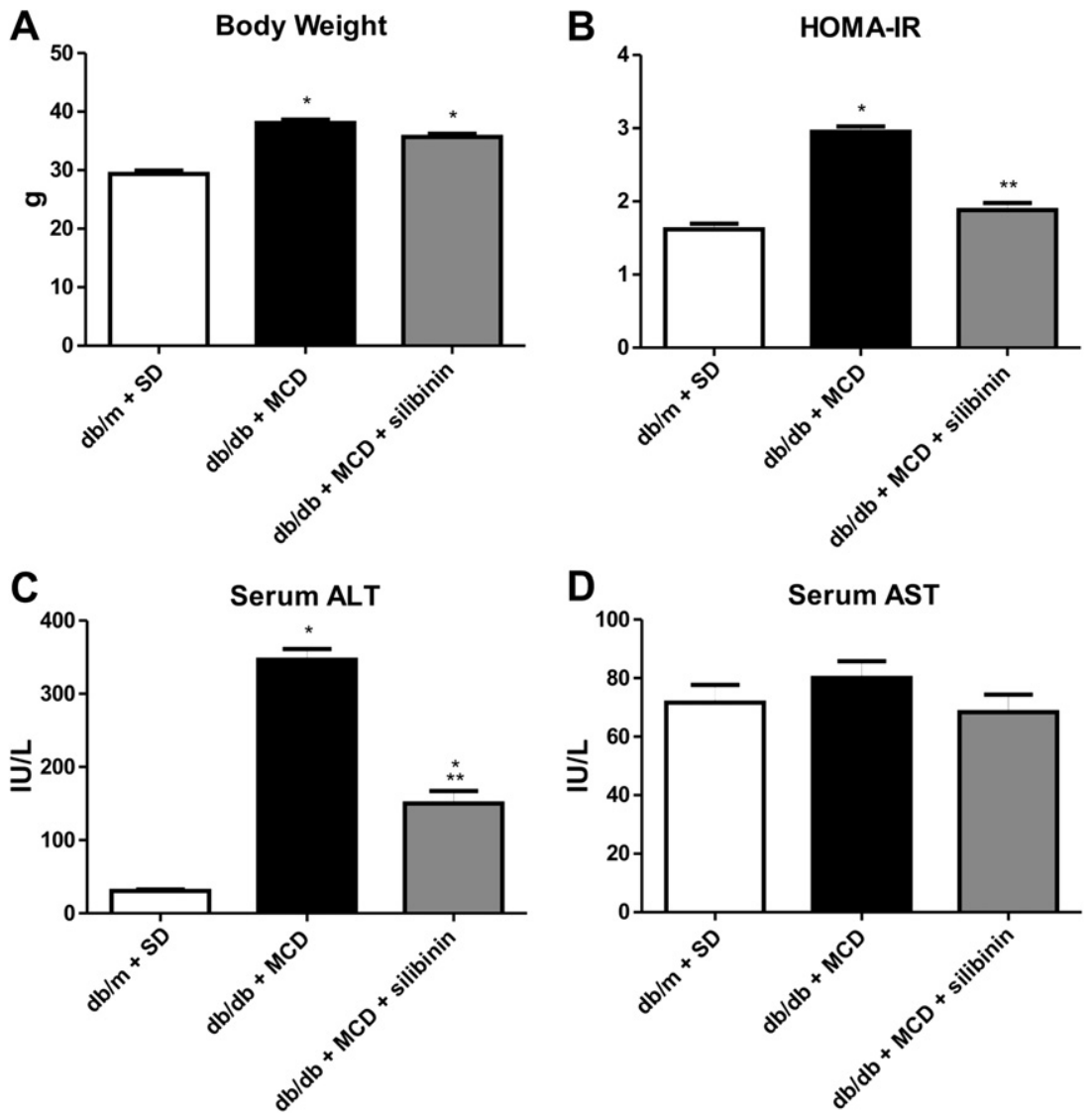

Fig 1. Effects of silibinin on metabolic parameters and serum transaminases. (A) Body weight was not significantly modified by silibinin administration, whereas $(\mathbf{B})$ insulin resistance, as assessed by homeostasis model assessment-insulin resistance, was improved by the treatment. (C) Serum ALT levels were markedly decreased in silibinin-treated mice. (D) Serum aspartate aminotransferase was unchanged in any group. $* P<.05 \mathrm{vs} \mathrm{db} / \mathrm{m}+$ SD. $* * P<.05 \mathrm{vs} \mathrm{db/db}+$ MCD.

Kruskal-Wallis was used for nonparametric data. $P<$ .05 was considered significant.

\section{RESULTS}

Effects on serum parameters and liver histology. $\mathrm{db} / \mathrm{db}$ mice fed an MCD diet, treated with vehicle, were insulin resistant, as shown by homeostasis model assessment-insulin resistance index (Fig 1); silibinin administration decreased fasting glucose and insulin, leading to normalization of homeostasis model assessment-insulin resistance (Fig 1). Vehicle-treated animals had a marked increase of serum ALT compared with lean controls, whereas aspartate aminotransferase levels were not modified (Fig 1); in silibinin-treated mice, ALT levels were significantly decreased (Fig 1). Consistently with the decrease of serum ALT, a marked improvement of liver histology was observed (Fig 2). In particular, liver sections of $\mathrm{db} / \mathrm{db}$ mice fed an MCD diet showed severe steatosis with an azonal pattern (Fig 2), moderate lobular inflammation, and diffuse hepatocyte ballooning. In the silibinin group, steatosis, lobular inflammation, and ballooning degeneration were markedly reduced (Fig 2); overall, NAFLD activity score was significantly decreased in treated animals (Fig 2). Masson's trichrome did not show fibrosis in any mice after 4 weeks of MCD diet (data not shown).

Effects on lipid homeostasis, oxidative stress, and NFkB activation. $\mathrm{db} / \mathrm{db}$ mice fed an MCD diet displayed an impaired liver expression of key metabolic enzymes involved in lipid homeostasis. Vehicle-treated animals had a reduction in hepatic mRNA levels of SCD- 1 and L-FABP, whereas AOX was not modified compared with lean controls (Fig 3). Of note, silibinin administration markedly induced gene expression of SCD-1, L-FABP, and AOX (Fig 3). Likewise, both SCD-1 and AOX enzymatic activities were increased after pharmacologic treatment (Fig 3). The level of TBARS, a marker of lipoperoxidation, was augmented in vehicle mice and strongly reduced in silibinintreated animals despite increased expression of AOX (Fig 3). 

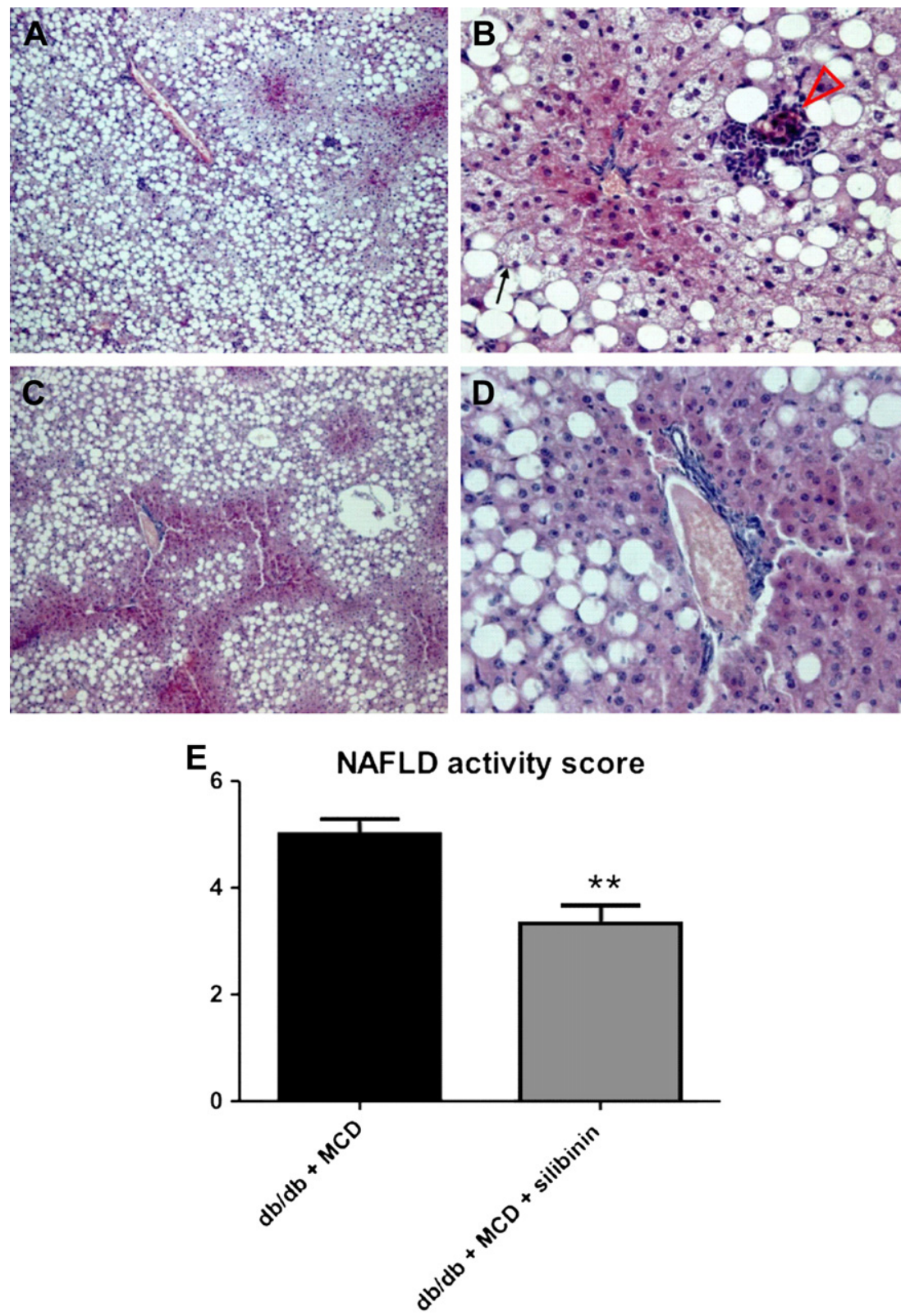

Fig 2. Effects of silibinin on liver histology. (A, B) Hematoxylin-eosin-stained liver sections of db/db mice fed an MCD diet showed severe azonal steatosis, diffuse hepatocyte ballooning (arrow), and scattered inflammatory foci (arrowhead). (C, D) Liver sections of silibinin-treated animals revealed an improvement in liver injury. (E) NAFLD Activity Score was significantly decreased by the treatment. ${ }^{*} P<.05 \mathrm{vs} \mathrm{db} / \mathrm{m}+\mathrm{SD}$. ${ }^{* *} P<.05$ vs $\mathrm{db} / \mathrm{db}+$ MCD. Magnification: $10 \times(\mathbf{A}, \mathbf{C}) ; 40 \times(\mathbf{B}, \mathbf{D})$. (Color version of figure is available online.)

ROS levels were increased in the liver of $\mathrm{db} / \mathrm{db}$ mice fed an MCD diet in comparison with lean controls (Fig 4); silibinin treatment decreased liver ROS to the levels of lean mice (Fig 4). Consistently, markers of nitrosative stress were also significantly increased in the liver of $\mathrm{db} / \mathrm{db}$ mice fed an MCD diet. Western blot analysis showed that iNOS expression was 9fold increased in vehicle-treated $\mathrm{db} / \mathrm{db}$ mice fed an
MCD diet (Fig 4). Silibinin treatment restored iNOS expression to the levels observed in the lean group (Fig 4). Nitric oxide (NO) is produced endogenously by iNOS and can rapidly react with superoxide anion to produce peroxynitrite leading to protein tyrosinenitration. Consistently with iNOS results, silibinin significantly reduced protein nitration as assessed by immunofluorescence for 3-NT. We found that 3-NT 

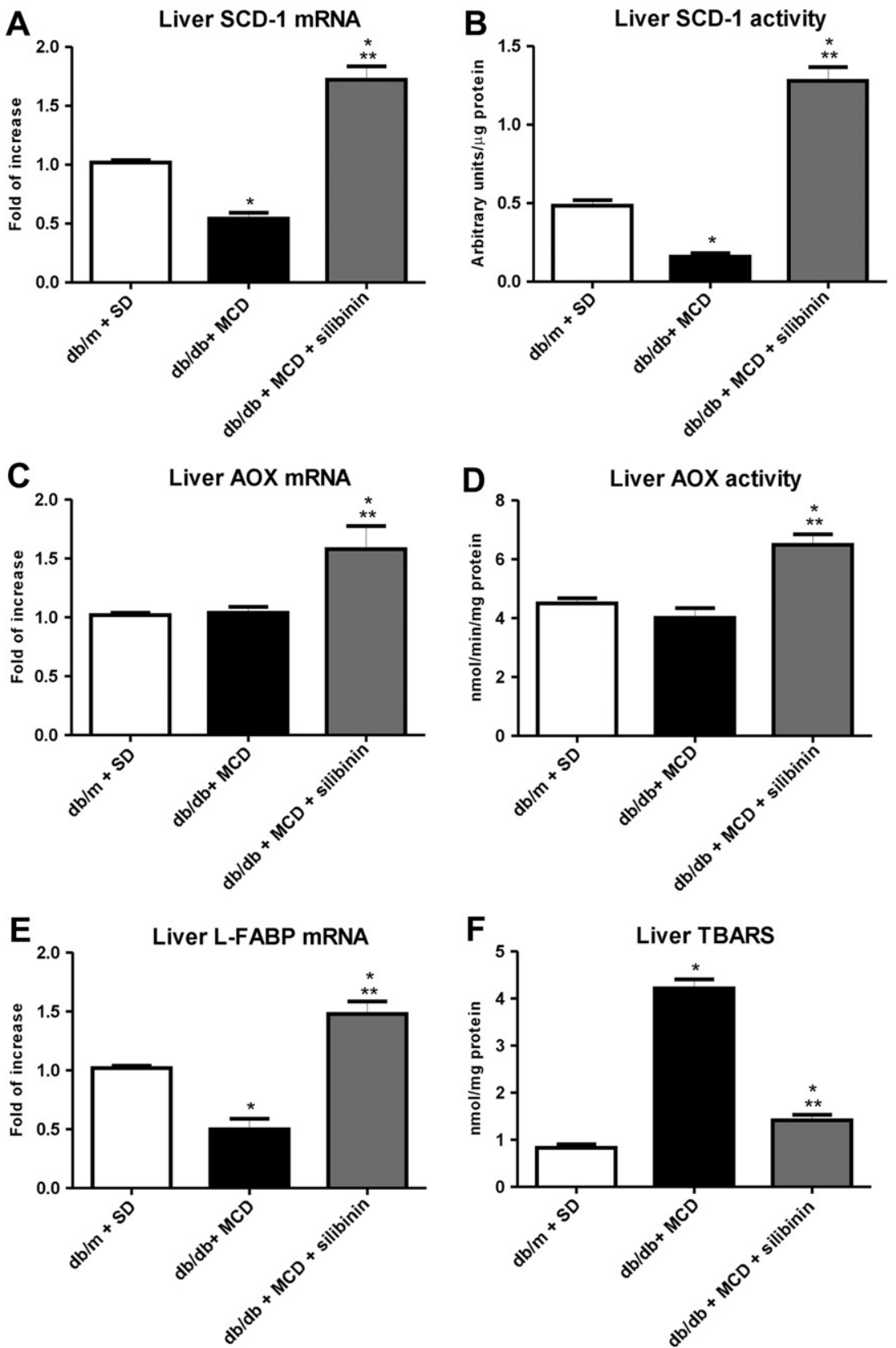

Fig 3. Effects of silibinin on liver lipid metabolic enzymes and lipid peroxidation. (A, B) Hepatic gene expression and activity of SCD-1 were reduced in $\mathrm{db} / \mathrm{db}$ mice fed an MCD diet compared with lean controls; by contrast, silibinin administration markedly enhanced SCD-1 mRNA levels and enzyme activity. (C, D) Gene expression and activity of AOX were induced by the treatment with silibinin in $\mathrm{db} / \mathrm{db}$ mice fed an MCD diet. (E) L-FABP was reduced in $\mathrm{db} / \mathrm{db}$ mice fed an MCD diet compared with lean controls and augmented by the treatment; $(\mathbf{F})$ the levels of TBARS, a marker of lipid peroxidation, were markedly reduced in silibinin-treated animals. $* P<$ $.05 \mathrm{vs} \mathrm{db} / \mathrm{m}+$ SD. $* * P<.05 \mathrm{vs} \mathrm{db} / \mathrm{db}+$ MCD.

is barely detectable in lean mice (data not shown), whereas a scattered positivity for 3-NT was present in the liver of vehicle-treated $\mathrm{db} / \mathrm{db}$ mice fed an MCD diet (Fig 4). Silibinin treatment resulted in a reduction of 3-NT immunofluorescence throughout the hepatic parenchyma (Fig 4). In agreement with oxidative-nitrosative stress findings, NFkB activity measurement showed a marked increase of p50 and p65 binding activity in vehicle-treated $\mathrm{db} / \mathrm{db}$ mice fed an MCD diet compared with lean animals; treatment with silibinin determined a decrease in the activity of both proinflammatory subunits (Fig 5). 
A

A Liver ROS

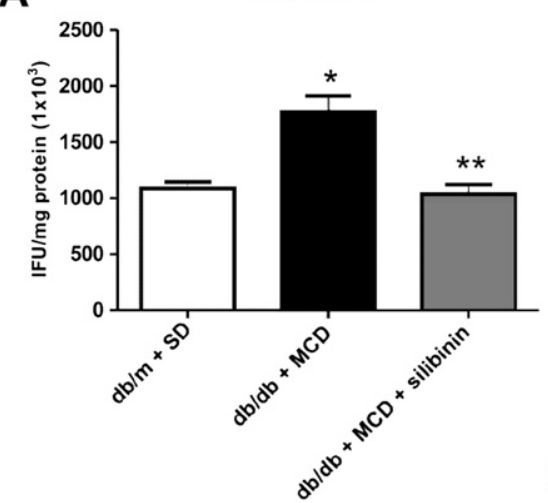

B
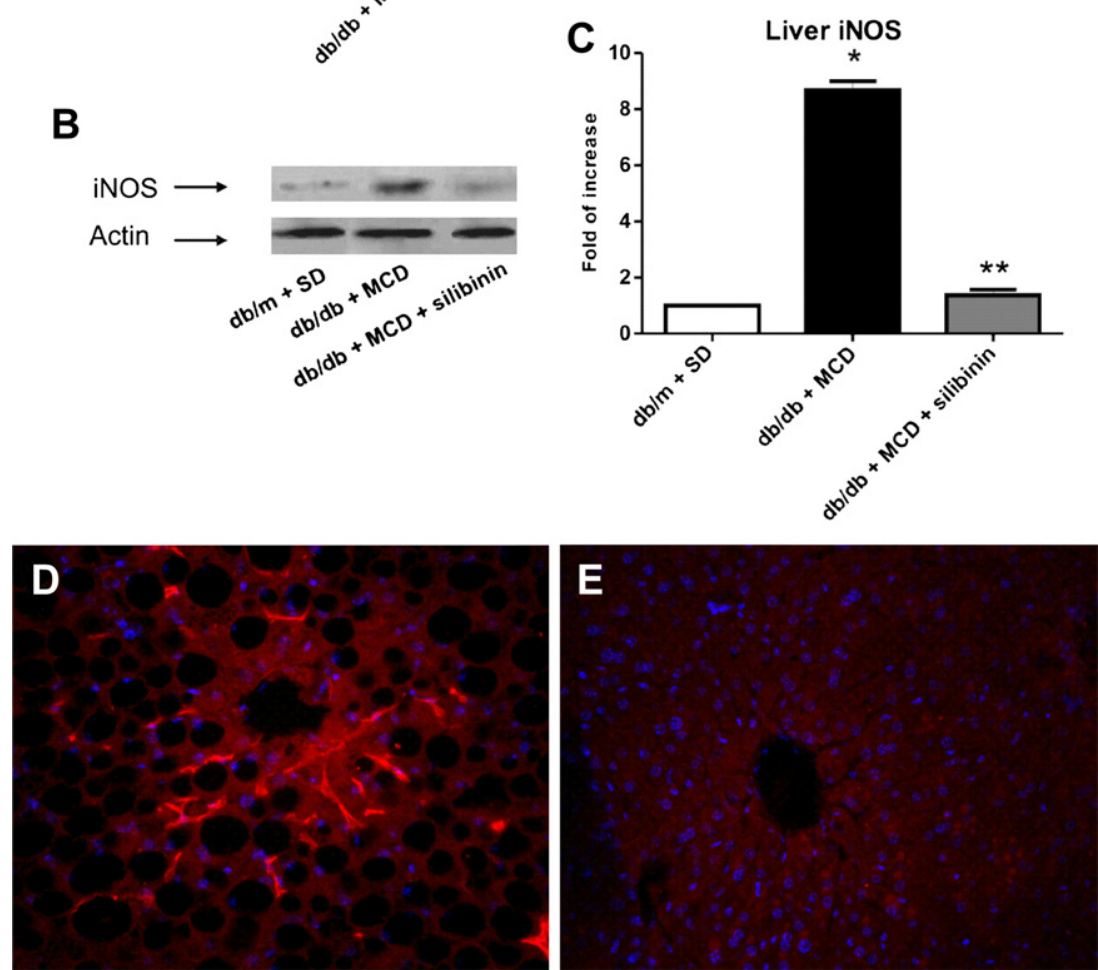

Fig 4. Effects of silibinin on liver oxidative-nitrosative stress. (A) Hepatic ROS were increased in vehicle-treated $\mathrm{db} / \mathrm{db}$ mice fed an MCD diet and significantly reduced in silibinin-treated animals. (B, C) Representative Western blot and densitometric analysis showing a marked increase of liver iNOS in vehicle mice and restored levels of iNOS in the silibinin group. (D, E) Immunofluorescence for 3-NT showed scattered positivity throughout the centrolobular zone in $\mathrm{db} / \mathrm{db}$ mice fed an MCD diet and reduced fluorescence in liver sections of mice treated with silibinin. $* P<.05 \mathrm{vs} \mathrm{db} / \mathrm{m}+\mathrm{SD}$. ${ }^{*} P P<.05 \mathrm{vs} \mathrm{db} / \mathrm{db}+\mathrm{MCD}$. (Color version of figure is available online.)

\section{DISCUSSION}

Silibinin is a polyphenolic compound contained in silymarin, a mixture of flavonolignans extracted from the seeds of milk thistle, which is widely used as hepatoprotective agent ${ }^{20}$ and has been reported to exert beneficial effects in patients with NASH. ${ }^{16,17}$ NASH pathogenesis is related to a puzzling crosstalk among liver, muscle, and adipose tissue about FFA fate, leading to an increased supply of FFA to the liver, which combined with de novo lipogenesis determines intrahepatic accumulation of triglycerides. ${ }^{6}$ In this study, we observed that silibinin reduces lipotoxicity in the liver by modulating the expression and activity of lipid metabolic enzymes, a main result of which seems to be the increase of SCD-1 gene expression and activity. Genetic or pharmacologic inhibition of SCD-1, the enzyme that converts saturated fatty acids to monounsaturated fatty acids, sensitizes cells to saturated fatty acid-induced death. ${ }^{26}$ SCD-1 is decreased in the MCD diet model on both lean ${ }^{26,27}$ and $\mathrm{db} / \mathrm{db}$ background, ${ }^{19}$ and SCD-1 knockout mice on the MCD diet present increased liver injury compared with SCD- $1+/+$ animals. ${ }^{26}$ Likewise, 

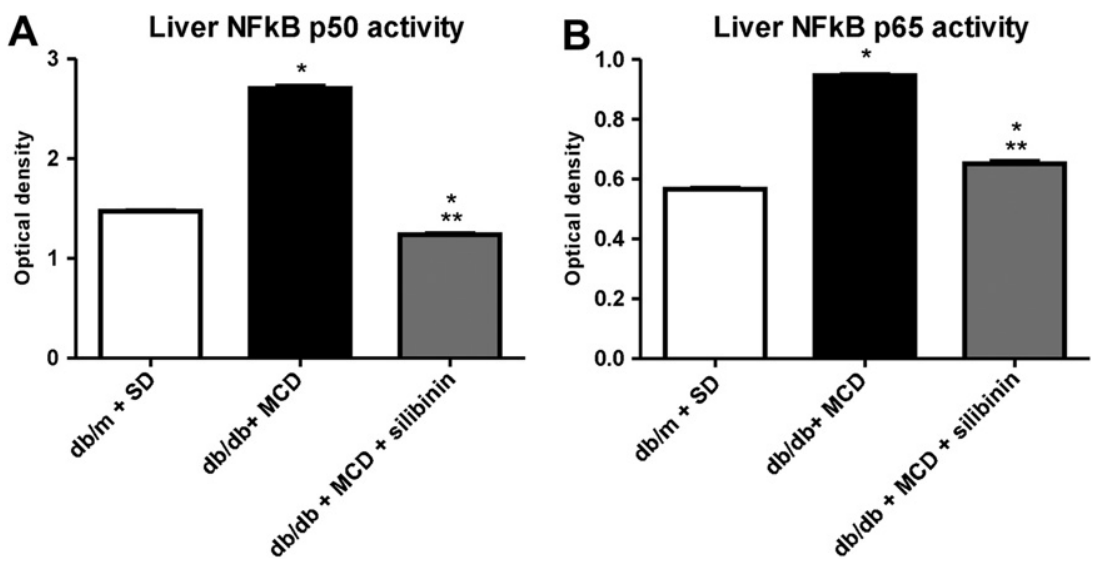

Fig 5. Effects of silibinin on liver NFkB activation. (A, B) Liver NFkB-p50 and p65 binding activities were markedly increased in $\mathrm{db} / \mathrm{db}$ mice fed an MCD diet compared with lean control mice; silibinin administration significantly decreased the activities of both subunits. $* P<.05 \mathrm{vs} \mathrm{db} / \mathrm{m}+\mathrm{SD}$. $* * P<.05 \mathrm{vs} \mathrm{db} / \mathrm{db}+\mathrm{MCD}$.

a decrease in L-FABP is associated with lipotoxicity in the MCD model ${ }^{28}$ because of the main role of L-FABP in FFA cellular disposal. ${ }^{6}$ Of note, we also found that AOX expression and activity were induced by silibinin treatment, thus suggesting it may enhance lipid oxidation. This effect occurs despite a decrease in lipoperoxidation, as suggested by reduced TBARS levels. It is well known that in the absence of efficient endogenous scavenging activity, FFA oxidation may lead to increased levels of ROS and RNS ${ }^{7}$ and to activation of inflammatory pathways, causing the progression of liver injury from fat to inflammation. ${ }^{8}$ Oxidative stress is considered a key phenomenon in the progression from fatty liver to steatohepatitis. ${ }^{29}$ Oxidative stress is mirrored by the increase of lipid peroxidation products (ie, malondialdehyde and hydroxynonenal) in patients with NASH and in animal models. ${ }^{30-32}$ The importance of oxidative stress in the pathogenesis of steatohepatitis is underscored by the use of several antioxidants, associated with variable success, in patients with $\mathrm{NASH} ;{ }^{33}$ a recent randomized controlled trial showed the efficacy of vitamin $\mathrm{E}$ in counteracting liver injury progression. ${ }^{34}$ There is evidence that both ROS and RNS contribute to hepatocyte damage and inflammatory/fibrogenic cells activation. ${ }^{34}$ Among RNS, peroxynitrite, which is generated from NO and the anion superoxide, determines cell injury by protein oxidation and nitrosylation (assessed by 3-NT levels), which causes dysfunction of several enzymes, ${ }^{35}$ including the components of mitochondrial respiratory chain. ${ }^{36}$ The effect of silibinin on nitrosative stress may explain the efficacy of this compound in preserving mitochondrial respiration, which has been demonstrated in a rodent model of iron overload ${ }^{37}$ and in another model of NASH. ${ }^{38}$
The cellular redox status is also one of the main stimuli for NFkB activation. ${ }^{39} \mathrm{NFkB}$ is the master transcription factor in the control of molecular pathways related to inflammation. ${ }^{39}$ NFkB activation has been demonstrated in a number of liver diseases both in humans and in mice, ${ }^{40}$ and has been shown in patients with NASH. ${ }^{41} \mathrm{NFkB}$ activity is directly related to parameters of oxidative stress in the liver of obese patients. ${ }^{42}$ Of note, the use of polyphenolic antioxidants, such as curcumin, determines NFkB inhibition displaying beneficial effects in experimental NASH. ${ }^{10}$ The inhibition of NFkB exerts therapeutic effects in different mouse models of NASH. In the MCD model, adenovirusmediated disruption of $\mathrm{NFkB}$, but not genetic inactivation of tumor necrosis factor- $\alpha$ signaling, protects mice from the initiation and perpetuation of liver injury. ${ }^{43}$ I-kappa-B kinase 2 inhibition recently was shown to attenuate liver injury in the orotic acid model of NASH. ${ }^{44}$ The current study evidenced that the activity of the p50 subunit and of p65 was markedly reduced in silibinintreated mice. Consistently with p65 inhibition, silibinin reverses the expression of iNOS, one of the main p65 downstream targets involved in NO production leading to nitrosative stress, ${ }^{45}$ confirming that this polyphenol also acts as an inhibitor of the iNOS pathway. ${ }^{46}$ Therefore, our data show that silibinin inhibits ROS/ peroxynitrite/NFkB signaling in this mouse model of NASH.

\section{CONCLUSIONS}

This study indicates that silibinin is able to modulate liver lipid homeostasis, reduces oxidative-nitrosative stress, and inhibits NFkB activation, key events in the pathogenesis of NASH. These findings support 
a pathophysiologic rationale for the use of silibinin in preventing liver injury progression in patients with NASH.

\section{REFERENCES}

1. Musso G, Gambino R, Cassader M, Pagano G. Meta-analysis: natural history of non-alcoholic fatty liver disease (NAFLD) and diagnostic accuracy of non-invasive tests for liver disease severity. Ann Med 2011;43:617-49.

2. Speliotes EK, Massaro JM, Hoffmann U, et al. Fatty liver is associated with dyslipidemia and dysglycemia independent of visceral fat: the Framingham Heart Study. Hepatology 2010;51:1979-87.

3. Salamone F, Galvano F, Li Volti G. Treating fatty liver for the prevention of cardiovascular diseases. Hepatology 2010;52:1174-5.

4. Korenblat KM, Fabbrini E, Mohammed BS, Klein S. Liver, muscle, and adipose tissue insulin action is directly related to intrahepatic triglyceride content in obese subjects. Gastroenterology 2008;134:1369-75.

5. Brunt EM. Histopathology of non-alcoholic fatty liver disease. Clin Liver Dis 2009;13:533-44.

6. Trauner M, Arrese M, Wagner M. Fatty liver and lipotoxicity. Biochim Biophys Acta 2010;1801:299-310.

7. Mantena SK, King AL, Andringa KK, Eccleston HB, Bailey SM. Mitochondrial dysfunction and oxidative stress in the pathogenesis of alcohol- and obesity-induced fatty liver diseases. Free Radic Biol Med 2008;44:1259-72.

8. Marra F. Nuclear factor-kappaB inhibition and non-alcoholic steatohepatitis: inflammation as a target for therapy. Gut 2008; 57:570-2.

9. Musso G, Gambino R, Cassader M, Pagano G. A meta-analysis of randomized trials for the treatment of nonalcoholic fatty liver disease. Hepatology 2010;52:79-104.

10. Leclercq IA, Farrell GC, Sempoux C, Dela PA, Horsmans Y. Curcumin inhibits NF-kappaB activation and reduces the severity of experimental steatohepatitis in mice. J Hepatol 2004;41:926-34.

11. Mira L, Silva M, Manso CF. Scavenging of reactive oxygen species by silibinin dihemisuccinate. Biochem Pharmacol 1994;48: 753-9.

12. Dehmlow C, Erhard J, de Groot H. Inhibition of Kupffer cell functions as an explanation for the hepatoprotective properties of silibinin. Hepatology 1996;23:749-54.

13. Pietrangelo A, Borella F, Casalgrandi G, et al. Antioxidant activity of silybin in vivo during long-term iron overload in rats. Gastroenterology 1995;109:1941-9.

14. Schumann J, Prockl J, Kiemer AK, Vollmar AM, Bang R, Tiegs G. Silibinin protects mice from T cell-dependent liver injury. J Hepatol 2003;39:333-40.

15. Li Volti G, Salomone S, Sorrenti V, et al. Effect of silibinin on endothelial dysfunction and ADMA levels in obese diabetic mice. Cardiovasc Diabetol 2011;10:62.

16. Federico A, Trappoliere M, Tuccillo C, et al. A new silybinvitamin E-phospholipid complex improves insulin resistance and liver damage in patients with non-alcoholic fatty liver disease: preliminary observations. Gut 2006;55:901-2.

17. Andreone P, Brisc M, Chiaramonte M, et al. Silybin conjugated with phosphatidylcholine and vitamin $\mathrm{E}$ improves liver damage in patients with NAFLD: the results of a randomized multicentre double-blind vs placebo trial. J Hepatol 2011;54(Suppl 1):S330-1.

18. Sahai A, Malladi P, Pan X, et al. Obese and diabetic $\mathrm{db} / \mathrm{db}$ mice develop marked liver fibrosis in a model of nonalcoholic steatohepatitis: role of short-form leptin receptors and osteopontin. Am J Physiol Gastrointest Liver Physiol 2004;287:G1035-43.
19. Rinella ME, Elias MS, Smolak RR, Fu T, Borensztajn J, Green RM. Mechanisms of hepatic steatosis in mice fed a lipogenic methionine choline-deficient diet. J Lipid Res 2008;49: 1068-76.

20. Kidd P, Head K. A review of the bioavailability and clinical efficacy of milk thistle phytosome: a silybin-phosphatidylcholine complex (Siliphos). Altern Med Rev 2005;10:193-203.

21. Ferenci P, Scherzer TM, Kerschner H, et al. Silibinin is a potent antiviral agent in patients with chronic hepatitis $\mathrm{C}$ not responding to pegylated interferon/ribavirin therapy. Gastroenterology 2008; 135:1561-7.

22. Bares JM, Berger J, Nelson JE, et al. Silybin treatment is associated with reduction in serum ferritin in patients with chronic hepatitis C. J Clin Gastroenterol 2008;42:937-44.

23. Osumi T, Hashimoto T, Ui N. Purification and properties of acylCoA oxidase from rat liver. J Biochem 1980;87:1735-46.

24. Woldegiorgis G, Spennetta T, Corkey BE, Williamson JR, Shrago E. Extraction of tissue long-chain acyl-CoA esters and measurement by reverse-phase high-performance liquid chromatography. Anal Biochem 1985;150:8-12.

25. Bradford MM. A rapid and sensitive method for the quantitation of microgram quantities of protein utilizing the principle of protein-dye binding. Anal Biochem 1976;72:248-54.

26. Li ZZ, Berk M, McIntyre TM, Feldstein AE. Hepatic lipid partitioning and liver damage in nonalcoholic fatty liver disease: role of stearoyl-CoA desaturase. J Biol Chem 2009;284:5637-44.

27. Rizki G, Arnaboldi L, Gabrielli B, et al. Mice fed a lipogenic methionine-choline-deficient diet develop hypermetabolism coincident with hepatic suppression of SCD-1. J Lipid Res 2006;47: 2280-90.

28. Gyamfi MA, Damjanov I, French S, Wan YJ. The pathogenesis of ethanol versus methionine and choline deficient diet-induced liver injury. Biochem Pharmacol 2008;75:981-95.

29. Koek GH, Liedorp PR, Bast A. The role of oxidative stress in nonalcoholic steatohepatitis. Clin Chim Acta 2011;412:1297-305.

30. Videla LA, Rodrigo R, Orellana M, et al. Oxidative stress-related parameters in the liver of non-alcoholic fatty liver disease patients. Clin Sci (Lond) 2004;106:261-8.

31. Serviddio G, Bellanti F, Tamborra R, et al. Uncoupling protein-2 (UCP2) induces mitochondrial proton leak and increases susceptibility of non-alcoholic steatohepatitis (NASH) liver to ischaemia-reperfusion injury. Gut 2008;57:957-65.

32. Gaemers IC, Stallen JM, Kunne C, et al. Lipotoxicity and steatohepatitis in an overfed mouse model for non-alcoholic fatty liver disease. Biochim Biophys Acta 2011;1812:447-58.

33. Sanyal AJ, Chalasani N, Kowdley KV, et al. Pioglitazone, vitamin E, or placebo for nonalcoholic steatohepatitis. N Engl J Med 2010; 362:1675-85.

34. Lirussi F, Azzalini L, Orando S, Orlando R, Angelico F. Antioxidant supplements for non-alcoholic fatty liver disease and/or steatohepatitis. Cochrane Database Syst Rev 2007;(1):CD004996.

35. Trujillo M, Ferrer-Sueta G, Radi R. Peroxynitrite detoxification and its biologic implications. Antioxid Redox Signal 2008;10:1607-20.

36. Garcia-Ruiz I, Rodriguez-Juan C, Diaz-Sanjuan T, et al. Uric acid and anti-TNF antibody improve mitochondrial dysfunction in ob/ ob mice. Hepatology 2006;44:581-91.

37. Masini A, Ceccarelli D, Giovannini F, Montosi G, Garuti C, Pietrangelo A. Iron-induced oxidant stress leads to irreversible mitochondrial dysfunctions and fibrosis in the liver of chronic iron-dosed gerbils. The effect of silybin. J Bioenerg Biomembr 2000;32:175-82.

38. Serviddio G, Bellanti F, Giudetti AM, et al. A silybinphospholipid complex prevents mitochondrial dysfunction in a rodent model of nonalcoholic steatohepatitis. J Pharmacol Exp Ther 2010;332:922-32. 
39. Gloire G, Piette J. Redox regulation of nuclear post-translational modifications during NF-kappaB activation. Antioxid Redox Signal 2009;11:2209-22.

40. Elsharkawy AM, Mann DA. Nuclear factor-kappaB and the hepatic inflammation-fibrosis-cancer axis. Hepatology 2007;46: $590-7$.

41. Ribeiro PS, Cortez-Pinto H, Sola S, et al. Hepatocyte apoptosis, expression of death receptors, and activation of NF-kappaB in the liver of nonalcoholic and alcoholic steatohepatitis patients. Am J Gastroenterol 2004;99:1708-17.

42. Videla LA, Tapia G, Rodrigo R, et al. Liver NF-kappaB and AP-1 DNA binding in obese patients. Obesity (Silver Spring) 2009;17: 973-9.
43. Dela PA, Leclercq I, Field J, George J, Jones B, Farrell G. NF-kap$\mathrm{paB}$ activation, rather than TNF, mediates hepatic inflammation in a murine dietary model of steatohepatitis. Gastroenterology 2005; 129:1663-74.

44. Beraza N, Malato Y, Vander BS, et al. Pharmacological IKK2 inhibition blocks liver steatosis and initiation of non-alcoholic steatohepatitis. Gut 2008;57:655-63.

45. Aktan F. iNOS-mediated nitric oxide production and its regulation. Life Sci 2004;75:639-53.

46. Kang JS, Jeon YJ, Kim HM, Han SH, Yang KH. Inhibition of inducible nitric-oxide synthase expression by silymarin in lipopolysaccharide-stimulated macrophages. J Pharmacol Exp Ther 2002;302:138-44. 